Noticias de salud ambiental ehp-spm

\title{
hand ENVIRONMENTAL HEALTH PERSPECTIVES
}

\section{La biología sintética}

Las implicaciones de un nuevo campo para la salud ambiental

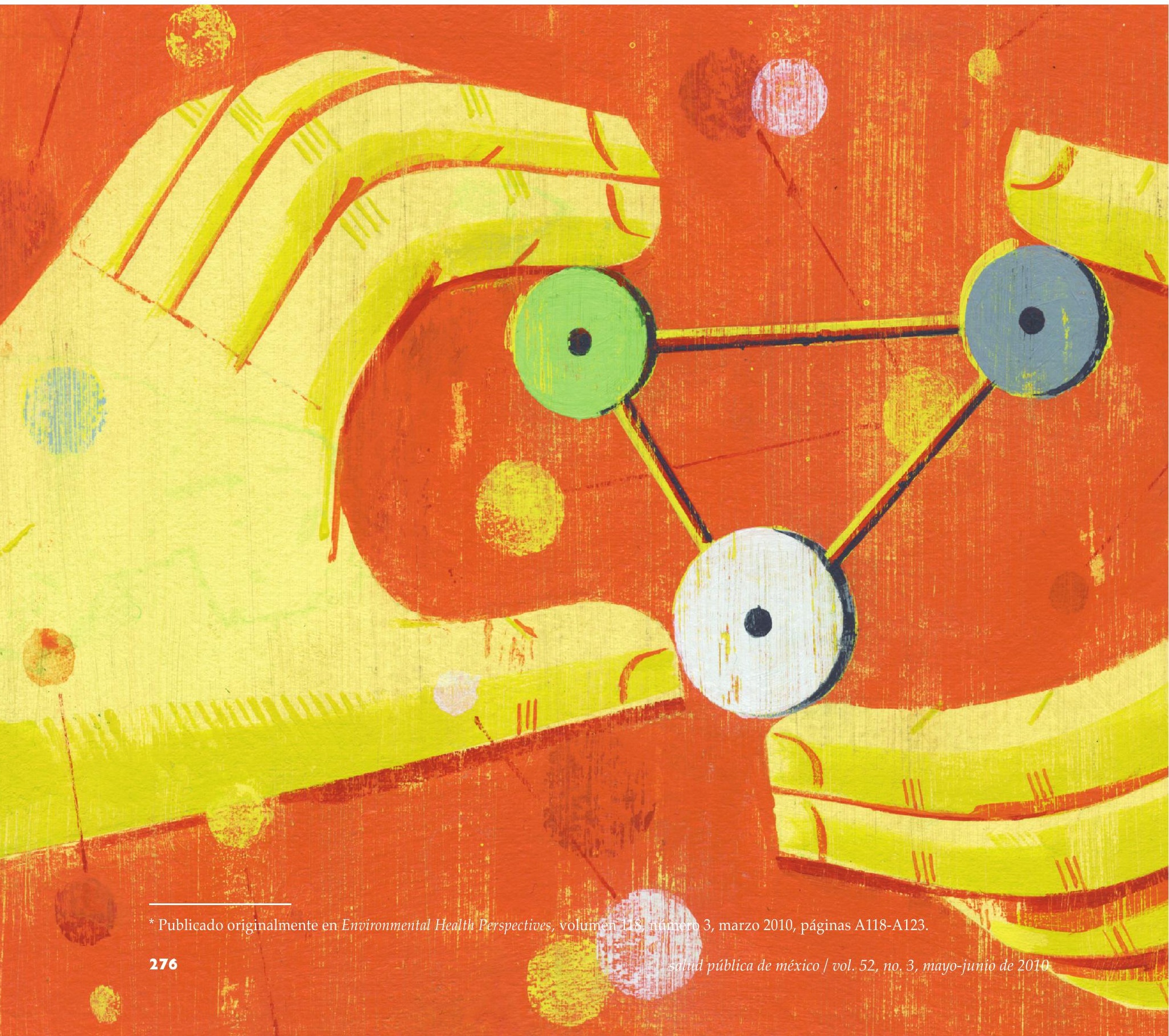


mente con la gasolina, el diesel o el combustible para aviones.

Pero si la biología sintética es emocionante, también resulta inquietante para quienes se preocupan por los riesgos que implica. Según algunos, los microbios modificados sintéticamente podrían escaparse y propagarse en condiciones naturales con consecuencias imprevistas. Otros advierten que la biología sintética tiene un elevado potencial de abuso. Ahora es posible adquirir por correo secuencias de ADN hechas según las especificaciones del cliente, a tan solo 40 centavos de dólar el par básico. Las compañías de síntesis genética no están obligadas legalmente a investigar los antecedentes de sus clientes, de modo que es posible que los terroristas lleguen a hacer armas biológicas virales desde cero, afirma Pat Mooney, director ejecutivo del Grupo ETC de Ottawa, Canadá.

Jay Keasling, profesor de ingeniería química de la Universidad de California en Berkeley, pionero de la investigación para elaborar la artemisinina, reconoce abiertamente los riesgos potenciales de este campo. "Lo peor que podría pasar es que alguien se vea lastimado por la biología sintética", dice. "Pero también estamos hablando de aplicaciones que justifican el avance del campo de una manera muy importante." Al igual que otros defensores, Keasling formula el potencial de la biología sintética en términos de cómo puede ayudar a resolver los peores problemas de la humanidad, muchos de los cuales están estrechamente entretejidos con la salud ambiental: la escasez de energía, la contaminación, la hambruna y las enfermedades.

"La población global, que ahora es de seis mil millones de personas, ascenderá a nueve mil millones en tan sólo treinta y cinco años," añade Craig Venter, famoso por haber realizado esfuerzos privados para decodificar el genoma humano y que ahora dirige el Instituto J. Craig Venter, organización de investigación basada en la genómica. "Nuestra... esperanza es que [la biología sintética] funcione de tal modo que no tengamos que destruir constantemente el medio ambiente para producir más alimentos. Lo mismo se aplica al combustible: necesitamos soluciones inteligentes."

\section{Un enfoque de los biocombustibles}

Dados el precio, la seguridad y las preocupaciones debidos a la contaminación por los combustibles fósiles, los biocombustibles ocupan un lugar prominente como un uso prioritario para la biología sintética; las cifras reunidas por el equipo de Rejeski demuestran que el Departamento de Energía de los Estados Unidos gastó más de 305 millones de dólares en investigación sobre biología sintética en el año fiscal 2009, y tiene una suma similar proyectada para el año en

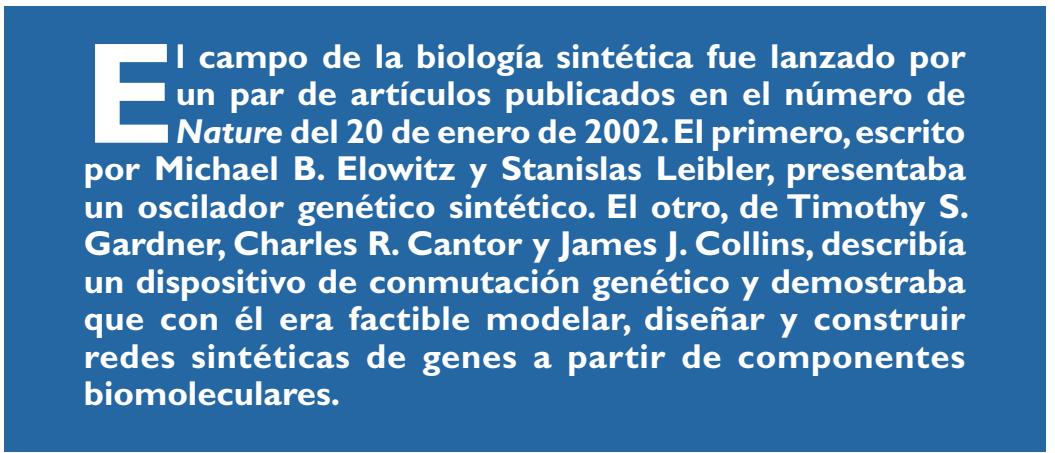

curso. (En cambio, el Departamento de Servicios Humanos y de Salud gastó aproximadamente 19 millones de dólares en el campo durante el año fiscal 2009, y aún no ha determinado la suma que gastará en 2010).

A diferencia de los combustibles fósiles, que al quemarse liberan dióxido de carbono $\left(\mathrm{CO}_{2}\right)$ que permanece por mucho tiempo en la atmósfera, los biocombustibles basados en plantas tienen una emisión neutra de carbono, lo que significa que el carbono que liberan al quemarse fue tomado del aire durante la fotosíntesis.

Los combustibles de primera generación actualmente disponibles -a saber, el etanol a base de maíz, el biodiesel y otros combustibles derivados de cultivos alimenticios- han resultado imprácticos como fuentes de energía, señala Toone. El etanol es corrosivo y se mezcla con el agua, de modo que no puede ser transportado por las tuberías. Y el biodiesel no puede quemarse en los motores de gasolina, que propulsan a la mayoría de los vehículos que circulan por los caminos. Es más, los combustibles de primera generación están relacionados con las inestabilidades en el precio de los alimentos y también con la deforestación en los países tropicales [para más información, véase "Alimentos vs. combustible: El desvío de las cosechas podría provocar más hambre", EHP 116:A254-A257 (2008)].

Los biocombustibles de la siguiente generación derivados de fuentes no alimenticias, tales como algas, cianobacterias y pasto aguja -una planta de maleza que crece en las tierras marginales, generando una enorme biomasa sin mucha aguaidealmente serán producidos de una manera más eficiente, aliviando en parte la presión sobre la agricultura. Los científicos están modificando células para que secreten productos intermedios de los combustibles (tales como lípidos y ácidos grasos) que pueden ser refinados y convertidos en combustibles. El pasado julio, Exxon- 
Mobil aportó 600 millones de dólares a la recientemente creada compañía de Venter, Synthetic Genomics, Inc., con el fin de extraer "biocrudo" de algas fotosintéticas que pueden ser refinadas y convertidas en gasolina, diesel y combustible para aviones.

El enfoque de Venter se basa en el concepto de fabricar biocombustible directamente a partir del $\mathrm{CO}_{2}$ en la atmósfera. Los organismos fotosintéticos tales como las algas fijan el $\mathrm{CO}_{2}$ del aire; después, utilizando la luz (como fuente de energía) y el hidrógeno del vapor de agua, reducen este $\mathrm{CO}_{2}$ a un producto rico en energía: la glucosa. La glucosa, un azúcar, está cargada de enclaces carbono-carbono. Y durante la respiración estos enlaces se descomponen en lípidos y otros hidrocarburos ricos en energía que idealmente podrían ser refinados y convertidos en combustible para el transporte.

Al modificar la estructura genética del alga, Venter y sus colegas apuntan a producir diferentes tipos de hidrocarburos, más similares a los que se encuentran en los combustibles fósiles. Dadas sus inquietudes como propietario, Venter no comenta sobre cómo está reprogramando las algas su compañía. Únicamente dice que éstas son "modificadas para bombear continuamente hidrocarburos hacia el medio ambiente [en lugar de acumularlos] y convertirlas en máquinas de producción en lugar de algo que simplemente cultivamos para matarlo o cosecharlo."

James Liao, profesor de ingeniería química y biomolecular de la Universidad de California, Los Ángeles, espera evitar por completo el refinado modificando las cianobacterias fotosintéticas que producen combustibles compatibles con los motores. Según se describe en el número de diciembre de 2009 de Nature Biotechnology, Liao y sus colegas desvían las vías celulares que normalmente intervienen en la síntesis de aminoácidos de modo que en lugar de éstos produzcan alcohol, específicamente butanol, que, según dice Liao, puede utilizarse en los motores actuales de combustión interna. "Lo bueno de las algas y de las cianobacterias es que no requieren de tierra cultivable," añade Liao. "Podemos utilizar las áreas costeras." En un artículo publicado en el mismo número de Nature Biotechnology, John Sheehan, coordinador de un programa científico del Instituto del Medio Ambiente de la Universidad de Minnesota, describió los volúmenes de producción de Liao como "impresionantes", señalando que son "cinco o seis veces mejores que las estimaciones industrialmente relevantes para la producción de etanol de maíz y celulósico, y que incluso superan las estimaciones actuales para la productividad de aceite de algas."

Aun así, Liao reconoce que incluso con estos altos rendimientos se necesitarían millones de acres para cultivar suficientes microbios fotosintéticos para remplazar la gasolina y otros combustibles fósiles líquidos. Esto se debe en parte a que los fotones penetran únicamente $10 \mathrm{~cm}$ en los estanques y biorreactores donde se cultivan los microbios.

Toone, quien dirige la investigación sobre biocombustibles en la Agencia de Proyectos de Investigación Avanzada del Departamento de Energía (mejor conocido por sus siglas en inglés ARPA-E), admite que los biocombustibles derivados de la fotosíntesis requieren de enormes áreas de terreno independientemente de si se utilizan cultivos para energía o microbios. "Y esto nos lleva a otra opción que aún no ha sido explorada: el uso de organismos no fotosintéticos para producir

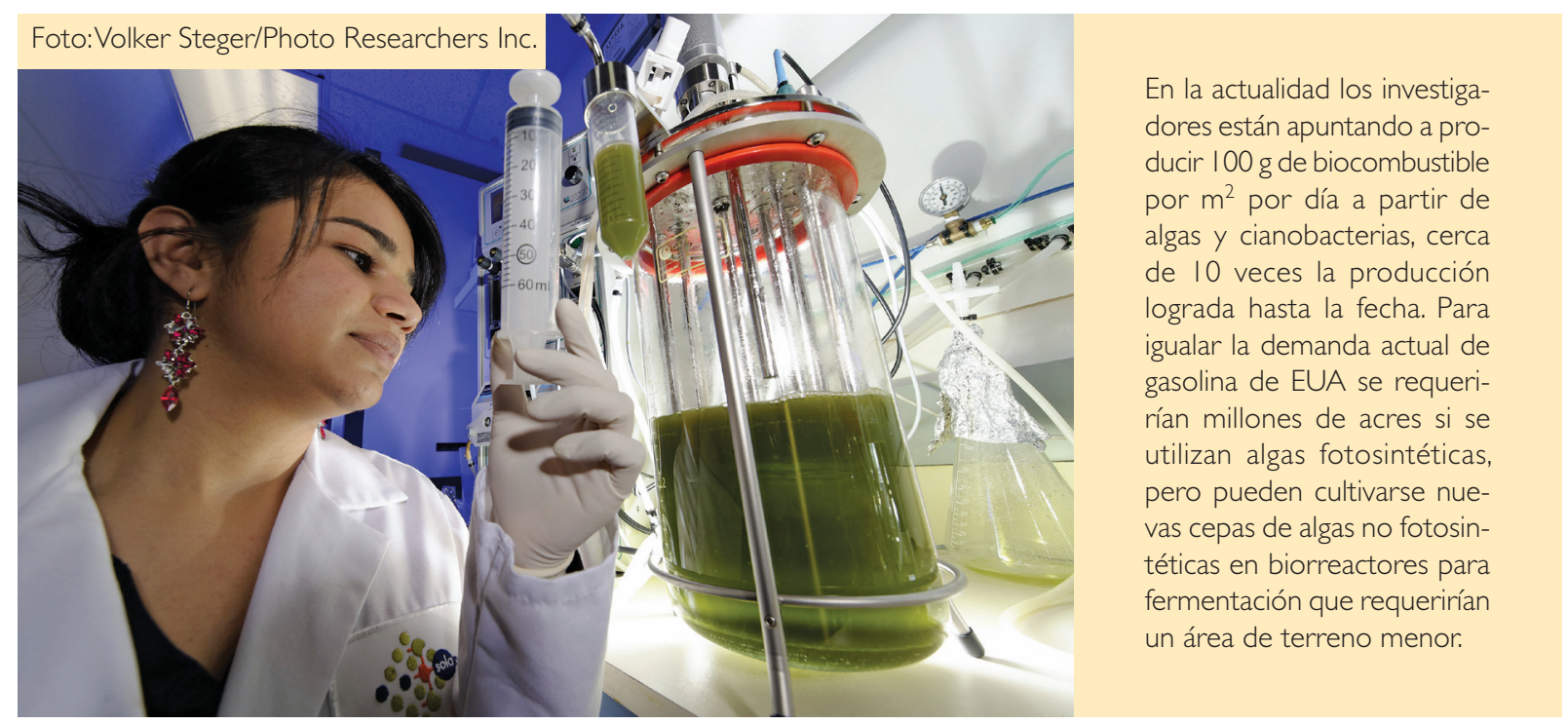


combustibles a partir del dióxido de carbono", dice Toone.

Los microbios no fotosintéticos toman energía de otras fuentes distintas de la luz, tales como los iones cargados que se encuentran en ciertos metales. Pero, al igual que sus equivalentes fotosintéticos, estos organismos no producen los compuestos tradicionales de los combustibles: por ejemplo, los microbios acetogénicos producen acetato durante la respiración, mientras que los metanógenos producen metano. "Necesitamos de la biología sintética para instalar nuevas vías y empezar a producir con estos organismos los combustibles que nos interesan", señala Toone. "Los bichos pueden ir a cualquier parte, incluso debajo de la tierra, y no es necesario extenderlos en una capa tan delgada porque no dependen de los fotones."

Robert Kelly, director del programa de biotecnología de la Universidad del Estado de Carolina del Norte, sugiere que la energía para los organismos no fotosintéticos podría provenir del hidrógeno, que algunos microbios anaeróbicos utilizan para reducir el $\mathrm{CO}_{2}$ a moléculas más complejas a base de carbono. Toone añade que se podrían modificar algunos microbios para utilizar la electricidad como fuente de energía. "Se podría generar esa energía con paneles solares, energía nuclear, incluso con energía eólica y con la acción de las olas", dice.

De la apabullante variedad de opciones para la fabricación de los combustibles de la siguiente generación, ninguna está lista aún para el momento de máxima demanda. Y aquellas que se consideran como las más prometedoras también tendrán que enfrentar tres retos básicos, según James Collins, profesor de bioingeniería de la Universidad de Boston y miembro principal del Instituto Wyss. "El primero es la escala: se necesita elevar la producción a niveles industriales", señala Collins.
"El segundo es la eficiencia, porque a medida que crece el tamaño de operación, el rendimiento del combustible probablemente disminuirá. $\mathrm{Y}$ el tercero es la economía; no se puede esperar tener un modelo de negocios viable si producir el equivalente a un dólar de gasolina tiene un costo de cuatro dólares. Si cualquiera de estas limitaciones queda sin superar, eso probablemente matará el proyecto."

Robert Carlson, directivo de Biodesic, compañía de diseño de bioingeniería de Seattle, Washington, no necesariamente ve la escala como un motivo de ruptura cuando se trata de comercializar las aplicaciones del biocombustible. Por el contrario, el 23 de febrero de 2009 escribió en un ensayo titulado "Las nuevas biofábricas" que la biología sintética podría permitir la producción de combustible en los autos mismos: "En la primavera de 2007, los investigadores reportaron la construcción exitosa de una sintética que consta de 13 enzimas de diferentes organismos que pueden convertir el almidón en hidrógeno", escribió. Esto sugiere un futuro en que el azúcar o el almidón -sustancias que pueden adquirirse en cualquier tienda de abarrotes-serán lo que pongamos en los tanques de nuestros autos en lugar de gasolina."

Kelly añade que probablemente ningún enfoque servirá como una bala de plata para reemplazar por completo a los combustibles fósiles. "No nos vamos a limitar a un solo sistema", dice.

\section{Microbios sintéticos para la biorremediación}

Aparte de los nuevos combustibles, también se cita una mejor limpieza de los desechos peligrosos como una de las promesas ambientales de la biología sintética. La biorremediación ya es común en la limpieza de los derrames de petróleo; las bacterias Rhodococcus y Pseudomonas, entre otras, consumen y degradan naturalmente muchos componentes del petróleo, transformándolos en productos secundarios menos tóxicos. La utilización de microbios modificados para degradar las sustancias químicas más recalcitrantes, tales como las dioxinas, plaguicidas o incluso compuestos radioactivos, podría representar un ahorro de millones de dólares que de lo contrario se gastan en la excavación y el transporte por carretera de los suelos contaminados a vertederos de desechos peligrosos, según señala Gary Sayler, director del Centro de Biotecnología Ambiental de la Universidad de Tennessee en Knoxville. Pero la investigación en este campo -en desarrollo durante más de dos décadas- tiene aún que salir del laboratorio, dice Sayler. Los activistas, temerosos de las consecuencias ambientales inciertas, se han alineado rutinariamente en contra de la liberación de microbios modificados para realizar la limpieza, y la Agencia de Protección al Ambiente de EUA (en inglés, EPA) ha sometido a los organismos a protocolos exhaustivos de evaluación de riesgos.

Hoy en día, las agencias de servicios de salud están más dispuestas a considerar el uso de microbios genéticamente modificados para la limpieza, añade Sayler; pero aun así, no se dispone de la infraestructura requerida ni del financiamiento para proceder. La biología sintética podría ofrecer nuevas oportunidades, añade; pero los científicos necesitan explorar de qué manera las vías de degradación desarrolladas principalmente en la investigación sobre el Escherichia coli podrían funcionar para otros microbios más aptos para sobrevivir en los lugares contaminados.

Un destacado científico en esta área es Víctor de Lorenzo, director del Laboratorio de Microbiología Molecular Ambiental del Centro Nacional de Biotecnología de España. De Lorenzo utiliza microbios robustos que sobreviven en condiciones rigurosas 
-por ejemplo, la bacteria del suelo Pseudomonas putida-que "edita" remplazando genómicamente los genes no esenciales con circuitos metabólicos y regulatorios modificados que degradan los compuestos objetivo. "Estos nuevos circuitos dirigen a los microbios apartándolos de las fuentes de carbono de fácil acceso como la glucosa, y llevándolos hacia fuentes de alimento de más difícil acceso en las sustancias químicas industriales. En otras palabras, estamos desacoplando el metabolismo de la fisiología del microbio", explica.

Al eliminar todos los genes no esenciales, de Lorenzo puede crear lo que se conoce como un genoma reducido, o una célula minimizada. A la manera de tablas rasas que los científicos pueden programar añadiendo nuevos genes, estos constructos definen una vanguardia para la biología sintética.

Aparte de fabricar células animales borrando los genes innecesarios, los científicos también pueden generarlos poniendo en funcionamiento células vaciadas (cuyos cromosomas hayan sido eliminados) con genomas completamente nuevos construidos desde cero. Este es el enfoque que Venter está adoptando ahora. En 2008, él y su equipo de investigadores lograron una de las más grandes hazañas de la biología sintética: sintetizaron todo el genoma -485 genes codificadorespara el Mycoplasma genitalium, una bacteria simple. Según Venter, por lo menos 115 de esos genes pertenecen al tipo de los no esenciales y pueden ser eliminados sin dañar la funcionalidad del genoma. Actualmente el equipo de Venter está intentando utilizar un genoma bacteriano sintético para poner en funcionamiento la célula vaciada de una especie relacionada, M. capricolum.

Hasta ahora, según se reporta en el número de Science del 25 de septiembre de 2009, no lo han logrado. Venter explica que el M. capricolum rechazó el nuevo genoma de manera muy similar a como rechazaría un virus. "Estamos desarrollando métodos para eludir este problema", dice. Entre ellos se incluyen: la eliminación de las enzimas de restricción que utiliza el M. capricolum para cortar el material genético extraño (lo que dio lugar al reciente fracaso) o el unir grupos metilo al genoma sintético para protegerlo dentro de la célula. Si logran obtener éxito, Venter y sus colegas producirán una célula mínima que posea únicamente los genes necesarios para la vida.

No obstante, se discute si ese tipo de célula constituiría una forma de vida sintética, como han afirmado algunos. Petra Schwille, profesora del Centro de Biotecnología de la Universidad Tecnológica de Dresde, señala que el microbio de Venter no es tanto vida sintética como algo más análogo a un clon interespecífico. "Él está insertando el genoma de un organismo en el chasís de otro", explica. Eso es diferente de sintetizar una célula viva completa a partir de ácidos grasos y proteínas. "En mi opinión, esto es más como un robot bacteriano que algún tipo de vida sintética."

Venter hace hincapié en que su ambición al hacer este tipo de células siempre ha sido utilizarlas como plataformas para comprender los procesos vitales fundamentales. Sin embargo, Silver subraya que, independientemente de cómo se hagan, las células mínimas también podrían ser utilizadas como plataformas de manufactura básicas. Así como la funcionalidad de una computadora depende de los programas que se le carguen, explica, la funcionalidad de una célula mínima dependería de sus circuitos sintéticos. "Si quieres hacer combustible o fármacos, tienes que utilizar éste como tu organismo de plataforma", dice. "Es esencialmente un chasís universal sobre el cual aplicas todo lo demás como una capa."

\section{Regular el futuro}

Mientras tanto, los expertos disienten en cuanto al grado de riesgo que podrían representar estos microbios modificados. Keasling arguye que no compiten bien en condiciones naturales y que, es más, los científicos pueden modificar a los organismos para que mueran una vez que hayan completado su tarea, por ejemplo, después de que se hayan agotado los nutrientes contaminantes de los que

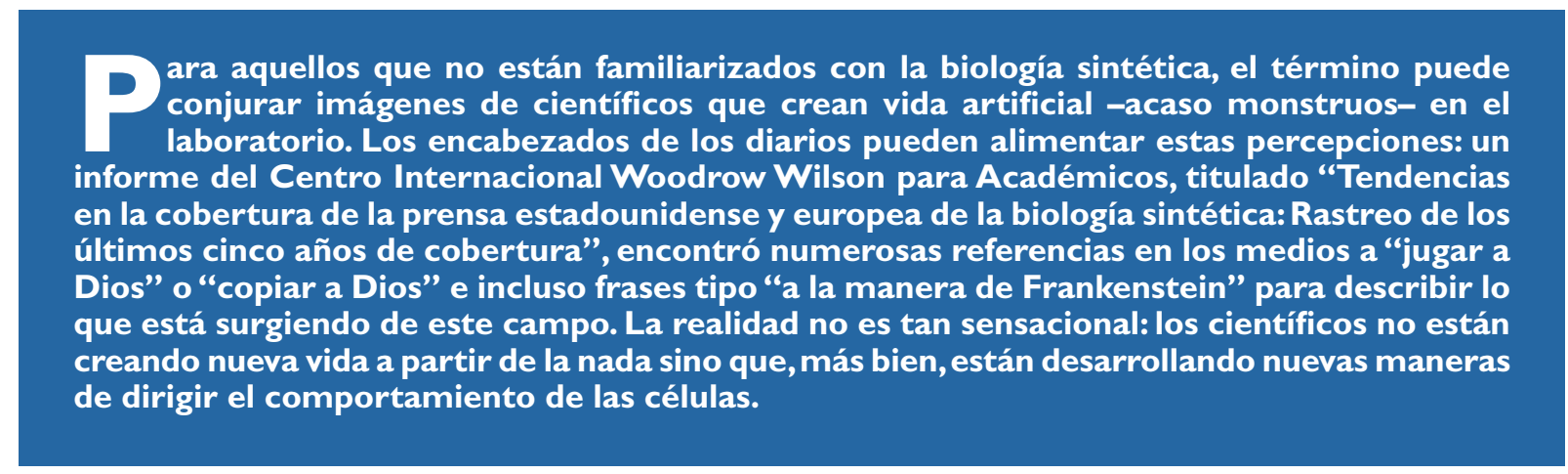


se alimentan. Y Collins ha creado contadores de ADN que hacen que mueran las células una vez que éstas se han replicado unas cuantas veces.

Aun así, como escribió Rejeski en el número de enero/febrero de 2010 de The Environmental Forum, "Una importante lección de la última Revolución Industrial es que los ganadores en esta carrera armamentista tecnológica no necesariamente son buenos para el medio ambiente." La biología sintética promete una galaxia de moléculas y sistemas "modificados específicamente para responder al ambiente externo (por ejemplo, para cambiar su estructura y su comportamiento en respuesta a la luz, a los campos electromagnéticos, al pH o a otras condiciones), o de hecho para unirse en estructuras totalmente nuevas", escribió. "Estas aplicaciones serán difíciles de entender con los métodos tradicionales de evaluación de riesgos."

Kitney señala que llegado un momento el punto de contacto entre las compañías sintetizadoras de genes y el público constituirá la primera línea para nuevas regulaciones. "Actualmente, la comunidad de investigadores en esta área es bastante pequeña", dice. "Pero a medida que crezca -y estoy convencido de que lo hará- necesitaremos pasar de los sistemas voluntarios a regulaciones más rigurosas que controlen las amenazas potenciales."

Mooney también advierte que el desarrollo de los biocombustibles podría seguir siendo una competencia inaceptable para los recursos agrícolas y consolidar la propiedad intelectual de los combustibles y su manufactura en manos de unas cuantas compañías. El informe del Grupo ETC de octubre de 2008, "Commodifying Nature's Last Straw? Extreme Genetic Engineering and the Post-Petroleum Sugar Economy" [¿Transformar el último reducto de la naturaleza en mercancía?: La ingeniería genética extrema y la economía

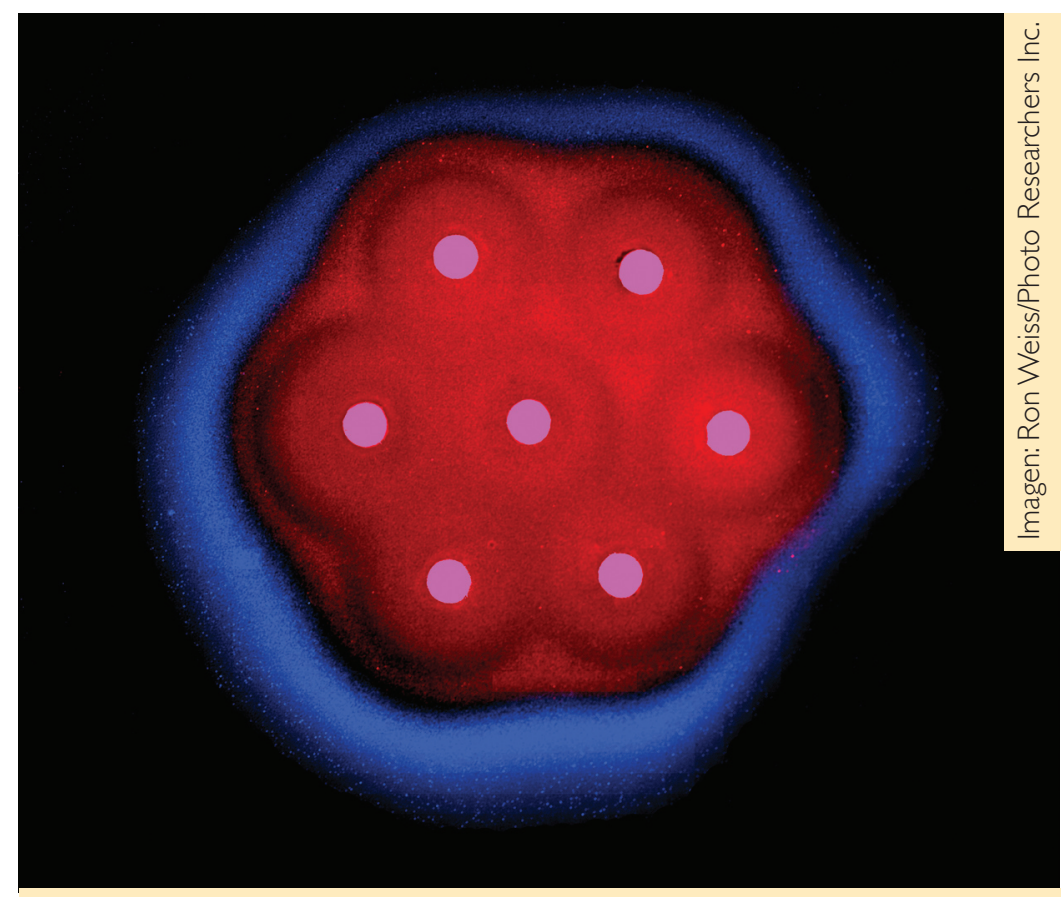

Arriba: Rick Weiss, del MIT, y sus colegas modificaron células "receptoras" de E. coli para evaluar qué tan lejos estaban de las células "emisoras" rosadas y reportar esta distancia expresando una proteína fluorescente (roja o azul) particular. El efecto se asemeja un tanto a la embriogénesis, en la que el ambiente materno proporciona estas señales utilizando gradientes químicos.

Abajo: William Shih, de Harvard, y sus colegas diseñaron un filamento único de ADN que se pliega formando un octaedro en nanoescala, utilizando una técnica llamada nano-origami. Estas estructuras diminutas podrían ser utilizadas en la manufactura de moléculas, como estructuras que transporten moléculas de fármacos directamente a las células enfermas, o en una cristalografía radiográfica.

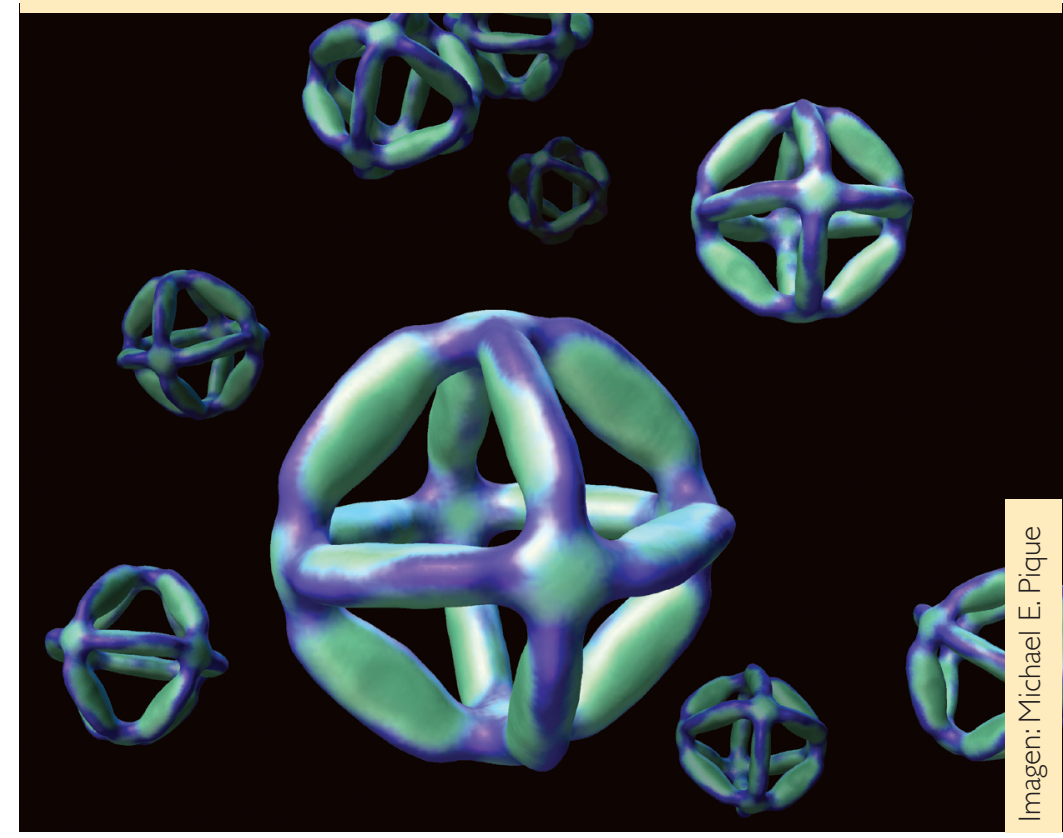


postpetrolera del azúcar], declara que "Los defensores de la biología sintética y la economía basada en los biocombustibles de la caña de azúcar dan por sentado que se dispondrá de una provisión ilimitada de biomasa celulósica. Pero ¿es posible cosechar sosteniblemente cantidades masivas de biomasa sin erosionar/degradar los suelos, destruir la biodiversidad, incrementar la inseguridad alimentaria y desplazar a los pueblos marginados?" Es más, el informe declara que el solo "ir más allá del petróleo" no hace frente a los patrones de consumo elevado que dan lugar a muchos de estos males ambientales.

Según Mooney, las regulaciones que rigen actualmente a la biología sintética son totalmente inadecuadas. "Esto no quiere decir que los riesgos sobrepasen a los beneficios potenciales", subraya. "No estamos hablando de un fracaso de la ciencia, sino del gobierno en términos de su capacidad de rastrear y regular una nueva tecnología poderosa," explica. "Esta capacidad de rediseñar la vida es mucho más vasta de lo que normalmente asociamos con la biotecnología."

Como lo expresó Rejeski en su ensayo publicado en Environmental Forum: "La EPA y las demás agencias ambientales tienen una oportunidad de esas que se dan sólo una vez cada siglo de colocar a la protección y las políticas ambientales al frente de un importante cambio en el modo en que producimos prácticamente todo." Lo que se necesita, señala Rejeski, es una autoridad central que coordine la investigación y la planeación en materia de biología sintética. Una entidad análoga, dice, podría ser la Oficina Nacional de Coordinación de la Nanotecnología, que organiza la investigación y el desarrollo federales, la información pública y las sesiones del Congreso en ese campo. "No hay suficiente participación pública en la ciencia de la biología sintética ni en sus implicaciones sociales y éticas, pero a juzgar por los que hemos analizado y encuestado, este es un tema que realmente va a dar lugar a discusiones", dice Rejeski. "La gente reacciona de una manera muy negativa a la frase 'biología sintética', y va a ser difícil pasar el hilo de la ciencia a través del ojo de la aguja de la opinión pública."

Aun así, Mooney elogia lo que considera un diálogo notablemente abierto entre los científicos y los expertos en políticas en los primeros días de esta tecnología. "No pueden ser sólo los científicos quienes tomen todas las decisiones aquí", dice.
"También necesitamos gobiernos que representen al pueblo, que puedan hablar a los científicos y más allá de ellos. Creo que si la gente tiene la oportunidad de meditar estas cosas cuidadosamente, terminaremos diciendo que no en algunos casos, pero en otros querremos saber cómo podemos utilizarla [la biología sintética] para resolver problemas."

El Maestro en Ciencias Charles W. Schmidt,
escritor científico galardonado de Portland, ME,
ha escrito para Discover Magazine,
Science, $y$ Nature Medicine 